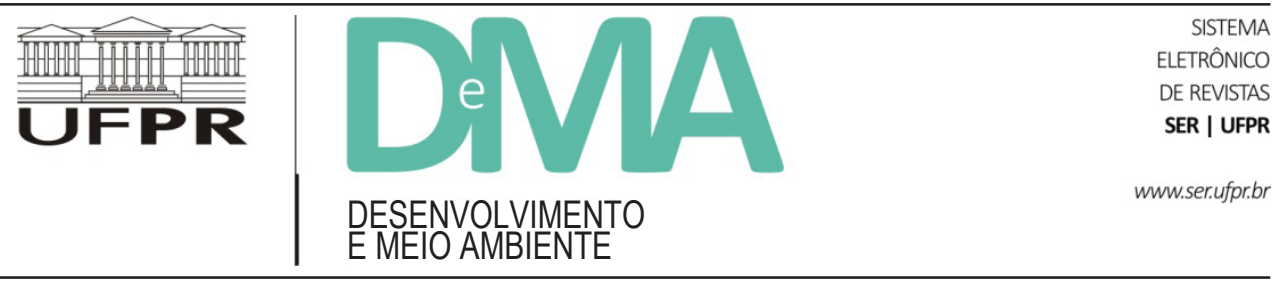

\title{
Limites e possibilidades para a gestão participativa da pesca no litoral do Paraná, sul do Brasil: experiências do Projeto "Nas Malhas da Inclusão"
}

\author{
Limits and Possibilities for the Participative Management of \\ Fisheries on the Coast of Paraná, Southern Brazil: Experiences \\ from the Project "Nas Malhas da Inclusão"
}

\author{
Guilherme Augusto CALDEIRA ${ }^{1 *}$, Tiago Vernize MAFRA ${ }^{1}$, Humberto Zontini MALHEIROS² \\ ${ }^{1}$ Programa de Pós-Graduação em Meio Ambiente e Desenvolvimento (PPGMADE), Universidade Federal do Paraná (UFPR), Curitiba, PR, Brasil. \\ ${ }^{2}$ Instituto de Pesquisas Ecológicas (IPÊ), Nazaré Paulista, SP, Brasil. \\ ${ }^{*}$ E-mail de contato: guicaldeirasocioambiental@gmail.com
}

Artigo recebido em 27 de agosto de 2015, versão final aceita em 1 de março de 2016.

RESUMO: $\quad$ No presente artigo, à luz de conceitos e formulações teóricas sobre a apropriação e a gestão compartilhada de recursos comuns, são analisadas algumas condições chave para a gestão da pesca no litoral do Estado do Paraná (Brasil) e apresentadas recomendações para a superação dos obstáculos e aproveitamento das oportunidades existentes. A análise foi baseada em experiências e informações obtidas no âmbito do projeto "Nas Malhas da Inclusão", um conjunto de ações desenvolvidas por meio de parceria entre ONGs, órgãos do governo envolvidos na gestão pesqueira e pescadores, com o objetivo de promover a gestão participativa da pesca no litoral do Paraná. A pesquisa identificou uma série de limitações do atual modelo de gestão, as quais comprometem os resultados obtidos e colocam os pescadores da região em condição de vulnerabilidade, não apenas pela ineficiência em promover a conservação dos recursos, mas também pela ilegalidade de boa parte de suas práticas de pesca. A superação dessas limitações requer ações consistentes e contínuas em diversas frentes, incluindo a construção de arranjos institucionais apropriados, a obtenção de informações, o empoderamento dos pescadores e o fomento a novas formas de organização social da produção. Infelizmente, tais ações parecem não fazer parte dos planos governamentais para o setor pesqueiro no Brasil e no Paraná.

Palavras-chave: gestão compartilhada; pesca de pequena escala; recursos comuns.

ABSTRACT: In this article, in the light of concepts and theoretical formulations on the appropriation and co-management of common resources, some key conditions for fishery management on the Paraná state coast (Brazil) are analyzed and recommendations to overcome obstacles and to use existing opportunities are made. The analysis was based on experiences and information obtained throughout the project "Nas Malhas da Inclusão", a set of actions developed through a partnership between NGOs, government agencies involved in fishery management, and 
fishermen in order to promote fishery co-management on the coast of Paraná. The research identified several limitations of the current management model, which compromise the results and put local fishermen in a vulnerable condition, not only for the inefficiency in promoting resources conservation, but also for the illegality of much of their fishing practices. The overcoming of these limitations requires consistent and continuous actions on many fronts, including the construction of appropriate institutional arrangements, the obtainment of information, the empowerment of fishermen and the development of new forms of social organization of production. Unfortunately such actions do not seem to be part of government plans for the fishing sector in Brazil and in Paraná.

Keywords: co-management; small-scale fishery; common resources.

\section{Introdução}

\subsection{Problemática e objetivos}

Assim como em diversas partes do Brasil e do mundo (FAO, 1999; Isaac et al., 2006; Abdallah \& Sumaila, 2007; Vasconcellos et al., 2007), a atividade pesqueira do litoral paranaense enfrenta uma crise de gestão marcada pela dificuldade em equacionar problemas como o declínio nos rendimentos das capturas, vulnerabilidade e subordinação socioeconômica de pescadores e a existência de uma série de conflitos relacionados ao uso e apropriação de recursos naturais (IPARDES, 1989; Kraemer, 1982; Polinari, 1998; Andriguetto-Filho et al., 2006; Caldeira \& Pierri, 2014).

No mundo todo, inclusive no Brasil, a constatação das limitações da gestão convencional, de enfoque biológico-reducionista e centralizadora dos processos de tomada de decisão nas mãos do Estado, contribuiu para a emergência, especialmente a partir da década de 1990, de uma nova abordagem para o tratamento da problemática da pesca: a gestão participativa, também chamada de gestão coopera- tiva, cogestão ou gestão compartilhada (Berkes et al., 2001; Abdallah \& Sumaila, 2007; Seixas et al., 2011). Em linhas gerais, esta abordagem pode ser definida como uma forma de parceria em que governo, usuários dos recursos em nível local e outros atores (ONGs, universidades, instituições de pesquisa, etc.) compartilham poder e responsabilidade na gestão (Pomeroy \& Williams, 1994; Berkes et al., 2001; Pomeroy \& Rivera-Guieb, 2006).

No litoral do Paraná, isso se expressa em uma série de iniciativas, tais como o envolvimento de pescadores na criação de medidas de ordenamento pesqueiro (Andriguetto-Filho et al., 2006; Franco et al., 2009; Andriguetto-Filho \& Pierri, 2012) e a criação de espaços de participação como o CORDRAP - Conselho Regional de Desenvolvimento Rural, do Artesanato e Pesqueiro e a Câmara Técnica de Pesca e Aquicultura (no âmbito do CONAPA - Conselho Gestor da APA de Guaraqueçaba). Visando potencializar esse processo e promover a gestão participativa da pesca da região, a organização não governamental IPÊ - Instituto de Pesquisas Ecológicas, em parceria com pescadores e órgãos governamentais envolvidos na gestão pesqueira local, desenvolveu o projeto "Nas Malhas da Inclusão".

\footnotetext{
1 O projeto foi financiado pelo MPA - Ministério da Pesca e Aquicultura. Entre os órgãos parceiros estavam o próprio MPA, o ICMBio - Instituto Chico Mendes de Conservação da Biodiversidade, o IBAMA - Instituto Brasileiro de Meio Ambiente e Recursos Naturais Renováveis, o CEPSUL - Centro de Pesquisa e Gestão de Recursos Pesqueiros do Litoral Sudeste e Sul, o IAP - Instituto Ambiental do Paraná, a SEMA - Secretaria de Estado do Meio Ambiente e Recursos Hídricos (do Paraná) e o BPAmb - Batalhão de Polícia Ambiental. Os autores do presente artigo atuaram como técnicos contratados pelo IPÊ para a execução do projeto.
} 
Os objetivos principais do projeto foram: 1) disponibilizar aos pescadores informações relacionadas ao manejo pesqueiro; 2) promover a comunicação entre pescadores e gestores; 3 ) levantar a percepção e sugestões dos pescadores em relação às normas de pesca existentes; 4) promover a participação dos pescadores na gestão pesqueira local; e 5) obter e divulgar informações para subsidiar a gestão participativa da pesca na região.

Este artigo descreve as atividades desenvolvidas pelo projeto, incluindo metodologias empregadas e resultados alcançados. Além disso, a partir de informações e experiências adquiridas e à luz de conceitos e formulações teóricas acerca da apropriação e gestão compartilhada de recursos comuns, são analisadas algumas condições para a gestão participativa da pesca no litoral do Paraná e apresentadas recomendações para a superação dos obstáculos e o aproveitamento das oportunidades existentes.

As informações analisadas foram obtidas por meio do levantamento bibliográfico e de técnicas de pesquisa participativa (Quivy \& Campenhoudt, 1992; Berkes et al., 2001; Seixas, 2005), incluindo entrevistas semiestruturadas e conversas informais (com pescadores, representantes da classe pesqueira e técnicos de órgãos do governo envolvidos na gestão), além de observações e registros realizados durante as atividades do projeto (visitas às localidades pesqueiras, reuniões com pescadores $\mathrm{e}$ representantes dos órgãos ambientais e dinâmicas de participação pública).

\subsection{A pesca no litoral paranaense}

A pesca profissional do litoral do Paraná abrange desde uma atividade artesanal ou mesmo de subsistência, realizada pelos donos dos instrumen- tos de produção com embarcações de pequeno porte ou de forma desembarcada, a empreendimentos empresariais, que produzem com força de trabalho contratada e utilizam embarcações com capacidade de várias toneladas e autonomia para operar durante duas semanas sem a necessidade de porto ou desembarque (Andriguetto-Filho et al., 2006). Mesmo considerando a frota de maior porte, a atividade pode ser considerada de pequena escala quando comparada à pesca realizada em outras regiões do Brasil e do mundo (Diegues, 1983; Berkes et al., 2001; Isaac et al., 2006).

A atividade parece ter relevância apenas regional, sendo pouco expressiva no contexto nacional (Andriguetto-Filho et al., 2006). Contudo, é o principal meio de vida direto e indireto de uma parcela significativa da população do litoral. A região abriga mais de 70 vilas ou comunidades pesqueiras (Noernberg et al., 2008) e, atualmente, conforme informações fornecidas pelas colônias de pescadores da região, existem aproximadamente 5.343 pescadores cadastrados na ativa.

Na plataforma continental, o arrasto de fundo para a captura de camarões é uma das técnicas mais difundidas. Os principais alvos são o camarão-sete-barbas (Xiphopenaeus kroyeri) e o camarão-branco (Litopenaeus schimitti). O último também é capturado pelas pescarias de caceio (rede de emalhe à deriva) e caracol (rede de emalhe tracionada pelo motor) (Andriguetto-Filho et al., 2006; Caldeira \& Pierri, 2014). Nos estuários - Baía de Guaratuba, ao sul, e Complexo Estuarino de Paranaguá, ao norte - o camarão-branco é capturado com o gerival, pequena rede de arrasto que opera à deriva (Andriguetto-Filho et al., 2006).

Entre os peixes alvo das pescarias estão bagres (Ariidae), cações (Carcharhinidae), cavalas (Scombridae), corvinas (Sciaenidae), linguados (Paralichthyidae), pescadas (Sciaenidae), robalos 
(Centropomidae) e tainhas (Mugilidae). Tanto em mar aberto como nos estuários, é utilizada uma grande variedade de práticas de emalhe, incluindo fundeio (redes fixas), cerco (rede disposta em círculo, cobrindo toda a coluna d'água), caracol, caceio (de superfície e de fundo) e arrastão de praia (lanços a partir da praia) (Andriguetto-Filho et al., 2006; Caldeira \& Pierri, 2014). Nos estuários, alguns peixes também são capturados com o uso de espinhéis e ocorre o uso de redes filó para a captura de iriko (larvas e juvenis de peixes, principalmente manjubas) (Andriguetto-Filho et al., 2006). A exploração de recursos bênticos também é bastante significativa nos estuários, com destaque para ostras (Crassostrea rhizophorae e Crassostrea brasiliana), sururus (Mytella guyanensis), siris (Callinectes spp.) e caranguejo (Ucides cordatus) (Miranda, 2003; Andriguetto-Filho et al., 2006).

\section{Normas de pesca vigentes no litoral do Paraná}

Em 2009 havia 30 instrumentos normativos vigentes para as práticas de pesca profissional no litoral do Paraná, incluindo Leis, Decretos, Portarias e Instruções Normativas. Desses instrumentos, quatro foram elaborados por órgãos estaduais (SEMA ou IAP) e 26 por órgãos federais (MMA - Ministério do Meio Ambiente, IBAMA, CEPSUL ou a extinta SUDEPE - Superintendência do Desenvolvimento da Pesca). As normas instituídas pelos órgãos estaduais abrangem o litoral paranaense ou localidades específicas da região. Dos instrumentos instituídos por órgãos federais, dez eram vigentes para todo o território nacional, dez eram válidos para as regiões Sul e Sudeste do Brasil e seis valiam apenas para o litoral do Paraná ou para determinadas localidades da região (Tabela 1) (Malheiros et al., 2009).

TABELA 1 - Quantidade de instrumentos normativos de acordo com o nível de governança, tipo e abrangência vigentes no litoral do Paraná em 2009.

\begin{tabular}{ccc}
\hline \multicolumn{2}{c}{ Características dos instrumentos normativos } & $\begin{array}{c}\text { Quanti- } \\
\text { dade }\end{array}$ \\
\hline $\begin{array}{c}\text { Nível de governo do } \\
\text { órgão emissor }\end{array}$ & Federal & 26 \\
& Estadual & 4 \\
Tipo de instrumento & Lei & 3 \\
legal & Instrução Normativa & 8 \\
& Portaria & 17 \\
& Resolução & 1 \\
Abrangência & Decreto & 1 \\
\hline Total de Instrumentos & Nacional & 10 \\
\hline
\end{tabular}

FONTE: Os autores, com base em Malheiros et al. (2009).

Ao todo, o conjunto de instrumentos normativos analisado estabelece 71 normas para as práticas de pesca e extração de recursos bênticos (Tabela 2). Isso inclui nove períodos de defeso (oito períodos de proibição da captura de determinados recursos e um período de proibição do arrasto de fundo); sete normas que proíbem a captura de determinadas espécies (pinípedes, cetáceos, tartarugas marinhas e dezenas de espécies ameaçadas de extinção); dez normas que estabelecem tamanhos permitidos para a captura (tamanhos máximos para a captura de robalos e tamanhos mínimos para a captura de dezenas de espécies de peixes e recursos bênticos); 26 normas referentes a limites espaciais (restrições impostas pela existência de Unidades de Conservação e áreas de exclusão ou de permissão de determinadas práticas) e 19 normas que regulam características dos apetrechos ou procedimentos (dimensões das redes, tipo de tração, equipamentos proibidos, etc.) (Malheiros et al., 2009). 
TABELA 2 - Quantidade de normas de pesca vigentes para o litoral do Paraná no ano de 2009, de acordo com o tipo de restrição.

\begin{tabular}{cc}
\hline Tipo de Restrição & Quantidade \\
\hline Defesos & 9 \\
Proibição de captura de determinadas espécies & 7 \\
Tamanhos mínimos e máximos de captura & 10 \\
Limites espaciais & 26 \\
Apetrechos e procedimentos de pesca & 19 \\
Total & $\mathbf{7 1}$ \\
\hline
\end{tabular}

FONTE: Os autores, com base em Malheiros et al. (2009).

O trabalho de fiscalização das normas de pesca é realizado pelo IBAMA, pelo IAP e pelo Batalhão de Polícia Ambiental - Força Verde, muitas vezes em parceria. Eventualmente, algumas operações de fiscalização pesqueira contam com a participação da Polícia Federal, Receita Federal e Capitania dos Portos, cada qual operando de acordo com suas atribuições.

\section{Atividades do Projeto "Nas Malhas da Inclusão"}

A partir de discussões entre a equipe técnica do IPÊ, representantes dos pescadores e técnicos dos órgãos ambientais, foi definido que os objetivos do projeto poderiam ser atingidos por meio de duas ações principais: elaboração e distribuição da "Cartilha da Gestão Participativa da Pesca do Litoral do Paraná" (Malheiros et al., 2009) e a realização dos "Seminários de Gestão Participativa da Pesca no Litoral do Paraná".

\section{1. "Cartilha de Gestão Participativa da Pesca do Litoral do Paraná"}

Elaborada em parceria com os órgãos ambientais, a cartilha apresenta uma compilação, atuali- zada até o final de 2009, da legislação pesqueira incidente na pesca profissional do litoral paranaense (normas de pesca; legislação ambiental para o transporte, acondicionamento e comercialização de recursos pesqueiros; direitos e deveres dos pescadores abordados em atividades de fiscalização; sanções aos infratores da legislação pesqueira). O material também contém informações sobre o processo de gestão pesqueira, tais como papel dos órgãos do governo e de outros atores (como ONGs e instituições de representação dos pescadores), caminhos para a participação no processo de gestão, objetivos de algumas normas e novidades em relação ao tema (como a implantação do Mapa de Bordo e do PREPS - Programa de Rastreamento de Embarcações Pesqueiras por Satélite). Os temas são abordados com linguagem simples e adequada à realidade local. A cartilha contém uma história em quadrinhos, mapas e ilustrações que auxiliam o entendimento das informações. Foram produzidos 2.000 exemplares, os quais foram distribuídos aos pescadores e outros atores envolvidos.

\section{2. "Seminários de Gestão Participativa da Pesca no Litoral do Paraná"}

Buscando maximizar o aproveitamento e ajustar os eventos às diferentes realidades locais, a estrutura, o funcionamento e os temas abordados nos seminários foram definidos a partir da interação entre a equipe técnica e demais atores envolvidos. Os eventos foram precedidos de intenso trabalho de divulgação por meio de convites a instituições, "corpo a corpo" nas localidades pesqueiras, parcerias com organizações de representação (Federação, colônias e associações de pescadores do litoral do Paraná), cartazes, chamadas em rádios, jornais impressos e emissoras de TV locais. As datas e 


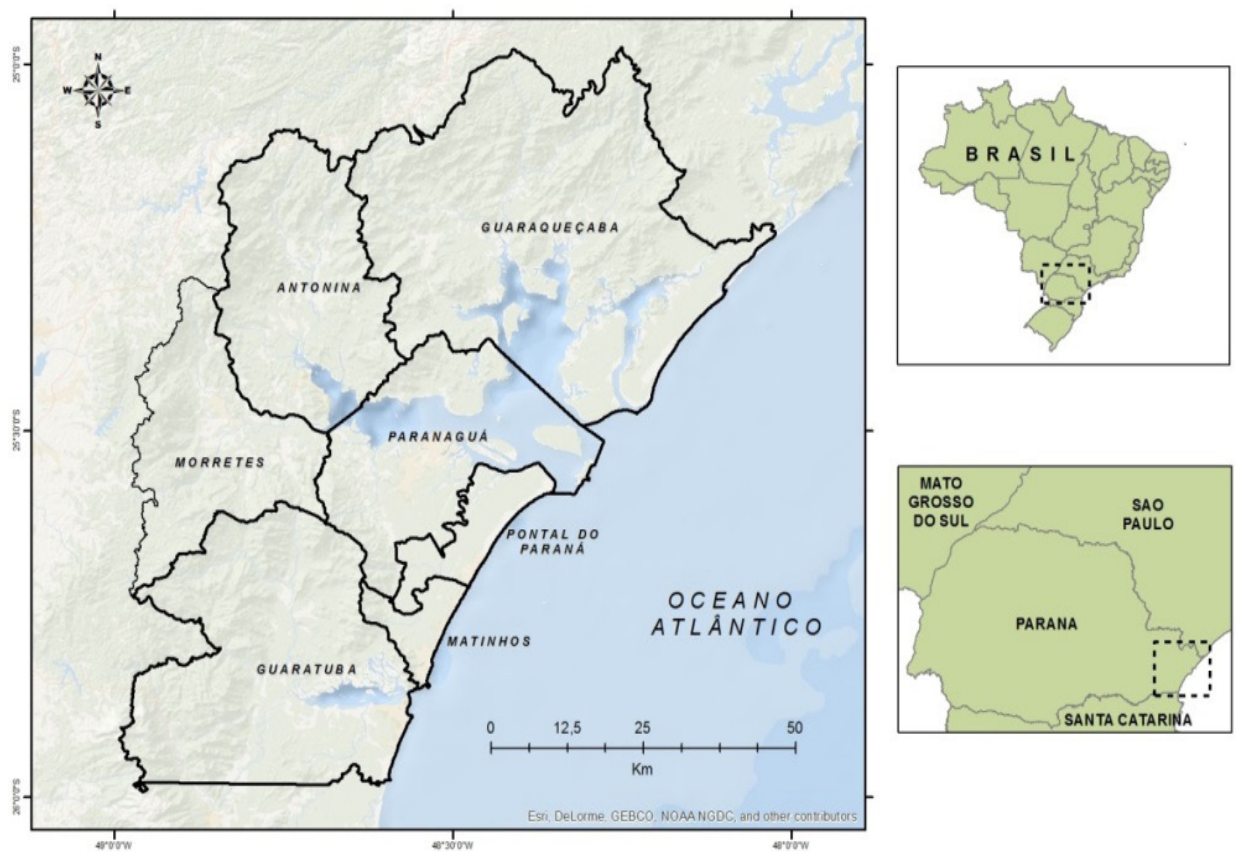

FIGURA 1 - Limites administrativos do litoral do Paraná com destaque para os municípios onde foram realizados os Seminários de Gestão Participativa da Pesca.

locais foram definidos pelos pescadores e, quando necessário, o projeto custeou gastos com transporte, estadia e alimentação de alguns participantes.

Foram realizados seis seminários, um em cada município do litoral em que a pesca profissional é significativa: Pontal do Paraná, Matinhos, Guaratuba, Paranaguá, Antonina e Guaraqueçaba (Figura 1). Os eventos ocorreram entre novembro de 2009 e agosto de 2010 e tiveram a duração de um ou dois dias cada. Ao todo, 636 pescadores participaram, o que representa $11,9 \%$ dos pescadores em atividade atualmente cadastrados nas colônias de pescadores do litoral do Paraná. O município com maior participação foi o de Guaratuba, onde estiveram presentes 280 pescadores, o que corresponde a $35 \%$ dos pescadores atualmente cadastrados na colônia de pescadores desse município. A menor participação ocorreu em Paranaguá, onde estiveram presentes apenas 36 pescadores, cerca de $4,8 \%$ do total de pescadores cadastrados na colônia de pescadores do município² (Tabela 3).

Cada seminário foi dividido em três fases principais: 1) abertura, 2) informação e 3) levantamento de sugestões de alteração na legislação pesqueira. Durante a abertura, após a inscrição dos participantes, ocorreram explicações sobre a origem e os objetivos dos eventos, bem como sobre o funcionamento dos mesmos (horários, programação e outras orientações). Depois disso, pescadores, lideranças locais e técnicos se apresentaram e falaram sobre suas expectativas em relação aos seminários. Ao fim da fase de abertura, foram firmados acordos e

\footnotetext{
2 O número de pescadores na ativa no ano de 2015 foi fornecido pelas Colônias de Pescadores dos respectivos municípios. Na ocasião dos eventos, as colônias estavam passando por recadastramento e não foi possível obter essa informação.
} 
TABELA 3 - Número de pescadores participantes dos seminários, população de pescadores em 2015 e número de participantes em relação à população de pescadores na ativa registrados no ano de 2015.

\begin{tabular}{cccc}
\hline Município & $\begin{array}{c}\text { Número de } \\
\text { participantes }\end{array}$ & $\begin{array}{c}\text { Pescadores na ativa } \\
\text { em 2015* }\end{array}$ & $\begin{array}{c}\text { Número de participantes em relação ao número de } \\
\text { pescadores na ativa em 2015 (\%) }\end{array}$ \\
\hline Guaratuba & 280 & 800 & 35 \\
Guaraqueçaba & 135 & 2.419 & 5,5 \\
Antonina & 90 & 724 & 12,4 \\
Pontal do Paraná & 54 & 450 & 12 \\
Matinhos & 41 & 200 & 20,5 \\
Paranaguá & 36 & 750 & 4,8 \\
Total & $\mathbf{6 3 6}$ & $\mathbf{5 . 3 4 3}$ & $\mathbf{1 1 , 9}$ \\
\hline
\end{tabular}

*Informação obtida junto às Colônias de Pescadores dos respectivos municípios.

estabelecidas condutas para o bom andamento do evento, tais como solicitar a palavra antes de se manifestar, não monopolizar a fala, aguardar o final da fala de outro participante para se pronunciar, manter o respeito e deixar claro quais "interesses pesqueiros" se pretende defender com determinada fala (individuais, de determinado grupo ou de todos os pescadores).

A fase de informação ocorreu por meio de exposições feitas por representantes dos órgãos do governo envolvidos na gestão pesqueira. Foram abordados os mesmos temas que constam na cartilha. Em alguns casos, de acordo com o tempo disponível e a possibilidade dos palestrantes, foi possível complementar e enriquecer as apresentações com outros temas, tais como a apresentação de informações sobre a condição dos principais estoques de recursos pesqueiros da região Sul/ Sudeste e pesquisas relacionadas à pesca no litoral do Paraná. As exposições foram feitas com o uso de projetor multimídia, observando-se cuidados para adequação da linguagem e dos recursos à realidade da classe pesqueira local. Sempre que pertinente, a equipe técnica do projeto realizou intervenções para facilitar e reforçar o entendimento de informações por parte dos pescadores. Após cada exposição, houve espaço para comentários e esclarecimentos de dúvidas dos pescadores presentes.

Durante as dinâmicas para o levantamento de sugestões de alteração na legislação, mediadores buscaram orientar as discussões para que fossem considerados os seguintes tópicos: impacto das alterações nos ecossistemas e nos recursos pesqueiros; efeitos econômicos no seu empreendimento pesqueiro; efeitos nos outros grupos ou categorias de pescadores; possibilidade de apoio político (de outros pescadores, dos órgãos ambientais, etc.) e condições para a fiscalização. Também houve diligência para estimular e facilitar a participação dos pescadores, especialmente os mais tímidos e com dificuldades de expressão em público. Para tanto, monitores circulavam entre os participantes, tomando notas de suas dúvidas, comentários e sugestões.

As dinâmicas foram conduzidas de acordo com estrutura e princípios metodológicos comuns definidos durante as fases de planejamento. Contudo, houve adaptações de acordo com as peculiaridades de cada evento (número de participantes, tempo disponível, sugestões dos participantes, grau de coesão social, divergência e conflitos existentes, etc.). Em Pontal do Paraná, as discussões iniciaram com a formação de dois grupos de trabalho 
mistos, com pescadores de vários tipos de pesca (arrasto de fundo, caça submarina, fundeio, caceio, etc.). Posteriormente, cada grupo apresentou suas sugestões, buscando justificá-las de acordo com os tópicos norteadores citados anteriormente. Em Guaratuba, seguindo a recomendação dos pescadores presentes, foram formados três grupos de trabalho para a discussão das sugestões, sendo um com pescadores que atuam no estuário, um com pescadores de pequena escala que atuam no mar aberto (arrasto, emalhe, fundeio, etc.) e um com pescadores de média a grande escala em mar aberto (baseada principalmente no arrasto de fundo). Em seguida, cada grupo apresentou suas sugestões, justificando-as de acordo com os tópicos norteadores propostos. Em Matinhos, Paranaguá, Antonina e Guaraqueçaba, não houve formação de grupos de trabalho e as sugestões foram discutidas e registradas em plenárias com a participação de todos os presentes, sempre buscando considerar os tópicos norteadores propostos.

Desde o início, foi informado que os seminários não tinham a pretensão de exaurir os debates e obter consenso acerca de sugestões de alteração das normas, o que seria inviável considerando a diversidade de interesses e a complexidade das questões envolvidas. Também foi ressaltado que as sugestões elaboradas não seriam encaminhadas aos órgãos ambientais, pois isso demandaria um processo mais amplo e aprofundado de discussão envolvendo pescadores de todos os municípios, o qual não estava contemplado no presente projeto. Entretanto, foi salientado que as discussões poderiam servir como via para identificar os principais interesses e instar um processo de organização social e negociação para o aprimoramento das normas. Visando contribuir para esse processo, ao fim de cada evento foram escolhidos representantes para defender as propostas em futuras instâncias de participação.

\section{Sugestões de alterações nas normas de pesca}

As sugestões de alteração nas normas de pesca construídas pelos pescadores que participaram dos seminários podem ser divididas em três tipos: 1) sugestões visando diminuir conflitos de uso; 2) sugestões visando diminuir restrições; e 3) sugestões visando à conservação dos recursos.

\subsection{Sugestões visando diminuir conflitos de uso}

Em Matinhos, Guaratuba e Paranaguá, pescadores de emalhe que atuam na plataforma propuseram a proibição do arrasto de fundo durante a noite, quando aumenta a possibilidade de danos às redes de fundeio. Não houve resistência da frota arrasteira. Em Guaratuba, os arrasteiros observaram que a medida não comprometeria seus resultados econômicos e lembraram que em reuniões anteriores teriam sido firmados acordos informais para a não realização do arrasto noturno. Em Pontal do Paraná, Matinhos e Guaratuba, para evitar acidentes com embarcações ou engates em redes de fundeio, foi sugerido que os praticantes da pesca de caceio de superfície deveriam permanecer no mar monitorando o deslocamento das redes.

\subsection{Sugestões visando diminuir restrições}

$\mathrm{Na}$ pesca de peixes, foi proposto o cancelamento das normas que limitavam em 15 metros a altura das redes de emalhe de superfície, proibiam o uso de redes com altura maior que a metade da profundidade do local de pesca e determinavam que as redes deveriam operar com a tralha superior 
a uma profundidade mínima de $2 \mathrm{~m}$ da superfície (Instrução Normativa do IBAMA n. 166, de junho de 2007). De acordo com os pescadores, tais normas inviabilizavam a pesca do cerco, considerada fundamental para a economia de muitas unidades produtivas. Ainda segundo os pescadores, esta prática não causa danos significativos aos estoques pesqueiros e ecossistemas marinhos, pois, além de ser realizada em pequena escala, é relativamente seletiva, capturando basicamente as espécies alvo (principalmente tainhas e cavalas) na fase adulta. Tal proposta foi apresentada nos seminários de Pontal do Paraná, Matinhos, Paranaguá e Guaratuba.

Nos municípios de Pontal do Paraná, Guaratuba, Paranaguá, Antonina e Guaraqueçaba, foi proposto o fim da proibição do uso de redes de fundeio nas praias do litoral do Paraná (Portaria do IAP n. 85, de junho de 2009). A proposta foi feita com o intuito de legalizar o uso de redes do tipo feiticeira nas regiões entre-marés de praias estuarinas e oceânicas, prática importante para a renda e subsistência de muitos pescadores, sobretudo aqueles desprovidos de embarcação. $\mathrm{Na}$ interpretação dos pescadores, a modalidade é pouco impactante, pois a extensão reduzida e os tamanhos de malha do petrecho resultam na captura de poucos indivíduos, geralmente em fase adulta.

Em Pontal do Paraná e Matinhos, foram sugeridas alterações na Portaria do IBAMA n. 171, de maio de 2008 (válida para as regiões Sul e Sudeste), que proibia a pesca nas regiões de desembocaduras estuarino-lagunares no período entre 15 de março e 15 de agosto. Segundo os proponentes, a norma restringia a safra da tainha em pontos tradicionais de arrastão de praia, o que coloca em risco a segurança econômica e alimentar de dezenas famílias e pode trazer prejuízos ao patrimônio cultural da região. Argumentou-se também que o reduzido esforço de pesca e as características dos equipamentos utili- zados (embarcações a remo, redes relativamente pequenas e malhas relativamente grandes) resultam em um impacto ecológico reduzido.

Para a pesca de camarões, foi sugerida a liberação do arrasto de fundo a partir de meia milha de distância da costa para as embarcações de pequena escala, em substituição ao limite imposto de uma milha (Instrução Normativa do MMA n. 29, de 6 de dezembro de 2004 - válida para o litoral do Paraná). A proposta surgiu nos municípios de Pontal do Paraná, Matinhos, Guaratuba e Paranaguá. Em todos os eventos, a maior parte dos pescadores reconheceu que a medida pode intensificar os impactos sobre os recursos pesqueiros e ecossistemas, sobretudo em função dos efeitos sobre a fauna acompanhante. Contudo, defendeu-se que o atual limite torna a prática pouco rentável ou mesmo inviável. Em Guaratuba, com o intuito de melhorar rendimentos econômicos imediatos, os arrasteiros de médio e grande porte propuseram a liberação do arrasto por embarcações acima de 10 Toneladas de Arqueação Bruta (TAB) a partir da distância de uma milha da costa, em substituição ao limite vigente de uma milha e meia (Instrução Normativa do MMAn. 29, de 6 de dezembro de 2004).

Em Matinhos, foi proposta a liberação do caracol com uso de malha $5 \mathrm{~cm}$ para a captura de camarão-branco na plataforma continental durante o período de defeso do arrasto. Atualmente, a Portaria do IBAMA n.12, de 20 de março de 2003, válida para o litoral do Paraná, proíbe o caracol, mas, durante o defeso do arrasto, permite o caceio de fundo com redes de malha igual ou superior a 5 $\mathrm{cm}$ para a captura do camarão-branco na plataforma continental. Segundo os pescadores, além de mais acessível economicamente, o caracol captura menor quantidade de fauna acompanhante quando comparado ao caceio de fundo. 
Também houve sugestões de alteração das normas para a pesca nos estuários estabelecidas pela Portaria do IBAMA n. 12. Em Antonina e Guaratuba foi proposta a liberação da pesca com espinhel e da captura de siri com o uso do puçá. Em Guaraqueçaba, foi proposta a liberação do cerco fixo de taquara e da pesca da manjuba com redes de filó. Argumentou-se que a proibição dessas práticas compromete significativamente os rendimentos econômicos e as condições de subsistência das populações de pescadores que vivem nos estuários. Em Pontal do Paraná, foi proposta a liberação da caça submarina nos estuários, desde que realizada por pescadores profissionais. Segundo os proponentes, durante boa parte do ano a caça submarina em mar aberto é inviabilizada por condições meteorológicas e de mar, o que resulta em dificuldades econômicas para pescadores que têm a prática como única ou principal fonte de renda e subsistência. Estes também alegam que, ao contrário da maioria das técnicas utilizadas na região, a caça submarina é altamente seletiva, o que pode minimizar impactos ecológicos.

\subsection{Sugestões visando à conservação dos recursos}

Durante os eventos, não foram apresentadas sugestões para reduzir o esforço da pesca local. Contudo, algumas visavam conter estratégias de intensificação ou aumento do potencial destrutivo de algumas práticas. Em Pontal do Paraná, Guaratuba, Paranaguá e Antonina, as sugestões de liberação das redes tipo feiticeira foram acompanhadas de sugestões de limites para esse tipo de pescaria (comprimento e tamanhos das malhas do petrecho, locais e períodos permitidos e número de petrechos por usuário). Em Pontal do Paraná, Matinhos, Antonina e Guaratuba, foram feitas sugestões quanto às características dos petrechos utilizados para as práticas de caceio boiado e cerco (restrições em relação ao comprimento, altura e tamanhos de malha das redes).

Também houve sugestões visando ajustar a legislação às características biológicas dos recursos. Em Guaratuba e Paranaguá, foi proposto que o período de defeso para o arrasto, vigente nos meses de março, abril e maio (Instrução Normativa do IBAMA n. 189, de 23 de setembro de 2008 - válida para as regiões Sul e Sudeste), fosse alterado para os meses de outubro, novembro e dezembro. Segundo alguns pescadores, o período seria mais adequado aos ciclos biológicos do camarão-sete-barbas, o que poderia promover a recuperação dos estoques. Essa percepção é reforçada pelo fato de que esses resultados já teriam sido observados em 2006 e 2007, quando o defeso aconteceu nesse período (Instrução Normativa do IBAMA n. 91, de fevereiro de 2006).

Em Guaratuba, Matinhos e Paranaguá, os pescadores solicitaram que a distância mínima da costa para a operação da pesca de traineiras e parelhas (Instrução Normativa do MMA n. 29, de 6 de dezembro de 2004 - válida para o litoral do Paraná) fosse ampliada de cinco para sete milhas. A intenção foi proteger estoques e ecossistemas usados pelos pescadores locais dos impactos da frota industrial de outros estados.

\section{Condições para a gestão participativa da pesca no litoral do Paraná}

\subsection{As fronteiras de uso e as conexões entre as escalas de gestão}

As fronteiras físicas ou padrões espaciais do sistema de recursos, dos usuários e da tecnologia utilizada para a sua apropriação exercem significativa influência no sucesso ou insucesso de sis- 
temas de gestão. A combinação entre esses fatores é fundamental para delinear as condições para a identificação dos usuários dos recursos e estabelecer as escalas geográficas e de organização humana em que a gestão deve ocorrer (Ostrom, 1990; Oakerson, 1992). No litoral do Paraná, a situação não é favorável nesse quesito. Algumas áreas de pesca utilizadas pelos pescadores locais são comumente acessadas por pescadores de outros locais, principalmente dos estados de Santa Catarina e São Paulo, e uma pequena parte da frota local realiza incursões aos estados vizinhos. Os recursos também são móveis, sendo acessados não apenas por usuários de diversas áreas e municípios do litoral paranaense, mas também por aqueles que atuam além do alcance da frota local. Em situações como essa, a natureza multi e transescalar dos fenômenos sociais e ecológicos envolvidos demanda que a gestão contemple múltiplas escalas, as quais devem ser conectadas e articuladas horizontalmente (através do espaço geográfico) e verticalmente (através dos vários níveis de organização humana) (Berkes, 2005).

A gestão dos recursos explorados pelos pescadores do litoral paranaense tem sido realizada em múltiplas escalas. Existem normas que abrangem todo o território nacional ou as regiões Sul e Sudeste, elaboradas por órgãos federais, e normas válidas apenas para o litoral do Paraná ou para áreas específicas da região implementadas pelos órgãos estaduais ou pelo IBAMA. Contudo, as escalas de gestão operam de forma independente e desarticulada, o que compromete a eficiência da gestão.

\subsection{Participação e representatividade dos pescadores}

A participação ou pelo menos a representação da maioria dos usuários constitui um elemento- -chave para a efetividade da gestão de recursos comuns. O envolvimento desses atores pode contribuir para que as normas sejam adequadas ao contexto socioecológico e às atividades sobre as quais incidem (eficientes na conservação, viáveis economicamente, fiscalizáveis, facilmente conhecidas e memorizadas, etc.). Essa adequação é essencial para a aceitação e a adesão dos usuários às normas de uso (Ostrom, 1990, 1992; Jentoft \& McCay, 1995; Berkes et al., 2001).

As informações obtidas apontam para a participação de representantes de pescadores no processo de elaboração de algumas das regras de relevante repercussão na pesca da região. Ao final da década de 1970, algumas restrições surgiram por demanda do setor pesqueiro, como a proibição do arrasto de fundo e do cerco de sardinha nas baías do litoral do Paraná (Andriguetto-Filho et al., 2006). Os limites espaciais para a pesca de arrasto, para a pesca de parelhas e para o cerco em mar aberto (Instrução Normativa do MMA n. 29, de 6 de dezembro de 2004 - válida para o litoral do Paraná), assim como o defeso da pesca de camarões nas baías (Portaria do IBAMA n. 133-N, de 8 de dezembro de 1994 - válida para o Estado do Paraná), também foram estabelecidos com a participação do setor (Andriguetto-Filho et al., 2006). As normas referentes ao defeso para o arrasto de fundo (como a Instrução Normativa do IBAMA n. 189, de 23 de setembro de 2008 - válida para as regiões Sul e Sudeste) têm sido geradas com a participação de pescadores paranaenses, seja enfatizando a importância da medida, seja sugerindo modificações, sendo que usualmente a diminuição nas restrições tem em vista melhores resultados econômicos (Franco et al., 2009). A Portaria do IBAMA n. 12, de 20 de março de 2003 (válida para o litoral do Paraná), que regula boa parte das práticas de pesca realizadas no litoral do estado, foi criada a partir de 
discussões e minutas sugeridas por representantes dos pescadores, pesquisadores e técnicos dos órgãos responsáveis pela gestão e fiscalização ambiental, principalmente o IBAMA, o IAP e o BPAmb.

Apesar da influência da classe pesqueira paranaense na elaboração de algumas regras, o atual modelo de gestão apresenta importantes limitações em termos de participação e representatividade. Boa parte das medidas não contemplou processos efetivos de identificação, comunicação e consulta dos atores potencialmente influenciados. E isso ocorre tanto pela falta de conexões institucionais transescalares e centralização da tomada de decisão em níveis mais elevados de governança quanto pela falta de diligência dos órgãos ambientais estaduais. Como resultado, tanto normas que abrangem escalas horizontais amplas (nível nacional ou regional) quanto normas que incidem localmente (todo o litoral paranaense ou áreas específicas desse espaço) têm sido elaboradas sem levar em conta a diversidade de interesses pesqueiros e especificidades socioecológicas da região. Entre os casos de maior repercussão estão as normas referentes às dimensões das redes de emalhe (Instrução Normativa do IBAMA n. 166, de junho de 2007, e Portaria do IBAMA n. 121-N, de 24 de agosto de 1998 -válidas para as águas sob jurisdição nacional), os tamanhos mínimos de captura de espécies marinhas (Instrução Normativa do MMA n. 53, de 22 de novembro de 2005 - válida para as regiões Sul e Sudeste), o ordenamento da pesca da tainha (Portaria do IBAMAn. 171, de maio de 2008 - válida para as regiões Sul e Sudeste), a implantação do defeso dos robalos (Resolução da
SEMA n. 016, de 30 de março 2009 - válida para o litoral do Paraná), e a proibição da colocação de redes a menos de meia milha náutica de distância das praias (Portaria do IAP n. 85, de 19 de junho de 2009 - válida para o Estado do Paraná).

Outro aspecto marcante envolvendo os processos de criação das normas é que os arrasteiros (pescadores e/ou proprietários de unidades produtivas de pequena a grande escala que se dedicam principalmente ou exclusivamente ao arrasto de fundo) expressam que o histórico de medidas implantadas no litoral do Paraná tem beneficiado principalmente a frota de canoas instalada na orla oceânica do estado. Essa percepção é embasada, sobretudo, na permissão do caceio com malha $5 \mathrm{~cm}$ durante o defeso do arrasto de fundo (Portaria do IBAMA n. 12, de 20 de março de 2003) e em iniciativas de assentamento de recifes artificiais na plataforma continental do estado ${ }^{3}$.

A literatura acerca do tema tem enfatizado que a percepção de iniquidades na capacidade de influenciar as decisões pode gerar conflitos que dificultam a efetivação de acordos e elevam os custos para a criação e operacionalização de instituições de gestão (custos de transação) (Ostrom, 1990; Oakerson, 1992; Baland \& Platteau, 1999). Esta dificuldade esteve intensamente presente nas atividades do projeto. As informações levantadas sugerem que essa percepção fez com que muitos pescadores se negassem a participar dos seminários. Além disso, os eventos foram marcados por afirmações, em tom de desabafo e indignação, de que os pescadores "não têm voz" no processo de gestão

\footnotetext{
Concebida a partir de demanda de pescadores da orla oceânica, a portaria permite a captura do camarão-branco no período em que o recurso é abundante, sem a concorrência dos arrasteiros. O assentamento de recifes artificiais foi uma iniciativa de pesquisadores da Universidade Federal do Paraná e de ONGs locais, como a Associação Mar Brasil (Brandini, 2013). Segundo pescadores, a ação reduziu as áreas propícias para o arrasto, inclusive em locais permitidos pela legislação. Além disso, a falta de balizamento e divulgação da localização das estruturas teria implicado em uma série de acidentes durante operações de pesca, resultando em danos aos equipamentos e situações de risco à tripulação.
} 
e que a intenção dos órgãos ambientais é acabar com a atividade pesqueira no litoral do Paraná. Em muitos casos, as intervenções eram prolongadas e em momentos inoportunos, afetando as atividades e demandando esforços intensos de mediação.

\subsection{Empoderamento dos pescadores}

O sucesso de estratégias de gestão participativa está condicionado ao grau de empoderamento dos atores envolvidos, entendido como a capacidade de uma pessoa ou grupo de influenciar nos processos de tomada de decisão que afetam suas vidas (Berkes et al., 2001). Essa característica depende de diversos fatores, como a tradição em ação coletiva, o nível de informação dos atores, a existência de lideranças qualificadas e organizações de representação apropriadas (Ostrom, 1990; 1992; Pomeroy \& Williams, 1994; Berkes et al., 2001; Gutiérrez et al., 2011).

No caso do litoral do Paraná, fatores como o histórico de reduzida oportunidade de participação e a falta de comunicação social no manejo limitam as condições para que os pescadores se aproximem, conheçam e influenciem o processo de gestão. A grande maioria desconhece aspectos relevantes da gestão pesqueira, tais como as organizações envolvidas e suas atribuições, os processos envolvidos na criação da legislação, e os direitos e deveres dos pescadores. Por outro lado, existem lideranças experientes e atuantes, com bom nível de conhecimento e relativa proximidade em relação ao processo de gestão. Em todos os municípios, dirigentes de colônias e associações de pescadores e/ou demais lideranças ligadas à atividade pesqueira desempenharam um papel fundamental em diversas fases do projeto. Apesar disso, o atual sistema de representação por colônias e associações se mostrou insuficiente para dar conta da diversidade de interesses e atores envolvidos. Além das dificuldades que as organizações enfrentam para conhecer, representar e mediar todos os interesses, foi possível observar que em determinados momentos algumas lideranças priorizam a defesa dos interesses individuais enquanto pescadores ou proprietários de unidade produtiva, deixando em segundo plano ou mesmo confrontando interesses de outros grupos de usuários que deveriam representar.

\subsection{Condições para o aprendizado das regras}

A simplicidade e a clareza das normas de uso são fatores fundamentais para o sucesso de estratégias coordenadas de apropriação de recursos comuns (Ostrom, 1990; 1992). No caso em exame, a diversidade de práticas de pesca e as limitações do processo de gestão (problemas de conexão entre escalas, participação e comunicação reduzidas, etc.) resultam em um quadro normativo complexo e pouco difundido entre os pescadores. A falta de clareza também gera dificuldades de interpretação. Um exemplo é a falta de definição precisa de termos técnicos usados para estabelecer limites espaciais, tais como "zonas de confluência dos rios" (Portaria do IBAMA n. 12, de 20 de março de 2003 - válida para o Estado do Paraná) e "regiões de desembocadura" (Instrução Normativa do IBAMAn. 171, de 9 de maio de 2008, válida para as regiões Sul e Sudeste). Ainda segundo os usuários, a falta de sinalização ou balizamento dos limites espaciais impostos pela legislação dificulta o cumprimento de algumas normas.

\subsection{Fiscalização e sanções aos infratores}

A fiscalização eficiente é fundamental para a o bom funcionamento das normas de uso (Ostrom, 
1990, 1992; Berkes et al., 2001). No litoral do Paraná, a abrangência espaço-temporal das ações de fiscalização é comprometida por restrições em termos de efetivo e infraestrutura. As condições para o patrulhamento são reduzidas e o trabalho é feito principalmente por meio do atendimento a denúncias e operações pontuais. A fiscalização também é comprometida pelo mau funcionamento de outros componentes do sistema de gestão. Estudos têm demonstrado que os problemas de compromisso e supervisão das normas estão relacionados com as condições em que elas são criadas (grau de envolvimento dos usuários), com a sua aceitação por parte dos usuários (percepção de que os benefícios decorrentes são maiores do que custos) e com o grau de complexidade das normas (condições para entendê-las e memorizá-las) (Ostrom, 1990; 1992), fatores tidos como críticos no modelo de gestão pesqueira vigente na região. Apesar das limitações, existem avanços importantes, incluindo a melhoria das condições logísticas e de recursos humanos experimentadas desde o final da década de 1990 e a implantação do PREPS, o qual aumentou a eficiência da fiscalização sobre embarcações de grande porte.

A aplicação de sanções graduadas e percebidas como justas pelos usuários também é um importante requisito para o sucesso de estratégias de manejo (Ostrom, 1990, 1992; Berkes et al., 2001). No litoral do Paraná, o tipo de abordagem de fiscalização e as sanções aplicadas aos infratores também têm sido motivo de descontentamento. Considerando o baixo grau de publicidade e a falta de clareza de algumas normas, os pescadores defendem que as abordagens deveriam priorizar a informação, e que para algumas normas, sobretudo as menos conhecidas, as sanções deveriam ser aplicadas apenas em caso de reincidência. Os usuários também reclamam do tipo de abordagem de fiscalização, alegando que se sentem humilhados ao serem abordados por policiais com arma em punho ou ao serem detidos por conta de infrações. Em 2009, esses conflitos motivaram a recomendação do MPF - Ministério Público Federal - para que os agentes de fiscalização não realizassem a prisão de pescadores de pequena escala no litoral do Paraná (Recomendação n. $03 / 09)^{4}$.

\subsection{Diversidade de interesses e conflitos entre pescadores}

A existência de clivagens e conflitos entre os co-usuários tende a elevar os custos de transação e dificultar a cooperação para a gestão compartilhada de recursos comuns (Ostrom, 1990; 1992; Berkes et al., 2001). A pesca do litoral do Paraná é marcada por conflitos decorrentes da competição pelo uso dos recursos pesqueiros. Um dos mais graves envolve os pescadores do litoral do Paraná, sobretudo os de pequena escala, e a pesca de grande escala sediada em outros estados das regiões Sul e Sudeste. Para os pescadores locais, a elevada subtração de recursos e a degradação dos ecossistemas causada por grandes traineiras, parelhas e arrasteiros "de fora" estão entre as principais causas do declínio nos rendimentos das pescarias na região. Aqueles que atuam na plataforma continental também reclamam dos danos causados às suas redes de emalhe, principalmente durante a noite. Um conflito semelhante envolve os pescadores de pequena escala

\footnotetext{
4 A demanda foi apresentada pela Federação das Colônias de Pescadores do Litoral do Paraná e contou com o apoio do IPÊ e de policiais do BPAmb, que emitiram pareceres e forneceram subsídios técnicos à recomendação do MPF. É bom esclarecer que a abolição de prisão em flagrante não isenta os infratores de serem responsabilizados pela infração, já que esses serão submetidos ao devido processo legal nas esferas administrativa e criminal.
} 
locais e a frota arrasteira de média e grande escala do litoral paranaense, sediada principalmente em Guaratuba. Para os pescadores de pequena escala, a atuação intensa destes arrasteiros contribui significativamente para o quadro de escassez de recursos e causa danos aos seus equipamentos de pesca instalados na plataforma continental. Já para os integrantes da frota arrasteira, a atuação dos pescadores de pequena escala em estuários e áreas rasas, consideradas fundamentais do ponto de vista ecológico, e o uso de práticas destrutivas, como as redes com malha de $5 \mathrm{~cm}$, também causam danos ecológicos expressivos. Também existem queixas de que pescadores de pequena escala exercem estratégias indevidas de apropriação territorial para coibir a atuação de barcos de arrasto em áreas permitidas pela legislação (como agressões verbais e a colocação de redes visando atrapalhar operações de arrasto). Na plataforma continental, a grande difusão do caceio de superfície com "rede-alta" intensificou a competição por espaço e aumentou o número de acidentes com a pesca de fundeio ou espera ${ }^{5}$. Segundo praticantes do fundeio, o grande deslocamento das redes-altas, somado à ausência de monitoramento por parte de alguns usuários, tem causado acidentes frequentes e prejuízos expressivos. Em Matinhos o problema parece ser grave, gerando clivagens entre grupos de pescadores.

\subsection{Conflitos entre interesses econômicos dos pescadores e as medidas de ordenamento pesqueiro}

A pesca profissional do litoral do Paraná é destinada principalmente ao mercado. $\mathrm{O}$ seu funcionamento é regido por dinâmicas e relações sociais próprias da produção mercantil que, além de fundamentais na configuração de resultados socioeconômicos e na distribuição da riqueza gerada pela atividade, influenciam as estratégias de uso e apropriação dos recursos pesqueiros (Caldeira \& Pierri, 2014). Para garantir uma boa posição nas relações de concorrência mediadas pela Lei do Valor, os pescadores devem manter determinados níveis de produtividade, produzindo a maior quantidade de pescado possível no tempo dedicado às capturas. Além das mudanças nos equipamentos, como alterações nas embarcações, aumento na quantidade e nas dimensões das redes e o uso de guinchos para $\mathrm{o}$ arrasto de fundo, a busca por maior produtividade estimula práticas potencialmente destrutivas, como a pesca em locais que costumam proporcionar maior rendimento, mas que possuem um papel-chave para o funcionamento dos ecossistemas e renovação dos recursos, como regiões próximas à costa e proximidades de canais, ilhas, parcéis e costões (Caldeira \& Pierri, 2014).

A interação entre o desenvolvimento tecnológico impulsionado pela dinâmica econômica e o distanciamento dos pescadores em relação ao processo de construção das normas de pesca gera incompatibilidade entre os seus interesses econômicos e os imperativos de conservação impostos pela atual legislação. Entre os pescadores existe a percepção generalizada de que o cumprimento de toda a legislação impediria boa parte das práticas em uso, restringiria demasiadamente os rendimentos de algumas práticas e resultaria na perda de investimentos em equipamentos. Ainda segundo esses atores, isso comprometeria significativamente a viabilidade econômica da pesca, colocando-os

\footnotetext{
${ }^{5}$ As redes-altas são redes de emalhe que podem ultrapassar 20 metros de altura e centenas de comprimento. No caceio de superfície, as redes podem se deslocar por dezenas de quilômetros em uma operação de pesca, muitas vezes cobrindo toda a coluna d'água. O petrecho também é utilizado para a prática de cerco ou lanço.
} 
em situação de vulnerabilidade socioeconômica, causando o abandono da atividade e trazendo prejuízos irreparáveis para a cultura pesqueira da região. Essa percepção está no cerne do conflito entre os pescadores da região e gestores, além de ajudar a explicar a insatisfação dos pescadores em relação às medidas de ordenamento e o predomínio, durante os seminários, de sugestões de diminuição das restrições.

As políticas de fomento visando à modernização e à industrialização da atividade pesqueira nacional, sobretudo da década de 1960 ao final da década de 1980, foram preponderantes para determinar as condições em que as unidades produtivas do litoral do Paraná se inserem no mercado. O aumento da produtividade gerado reduziu o valor de troca do pescado e diminuiu a competitividade das unidades produtivas locais, majoritariamente de pequena escala. Além de comprometer os rendimentos econômicos, isso foi fundamental para desencadear respostas de intensificação do esforço e busca de aumento da produtividade empreendidas pelos pescadores da região na tentativa de fazer frente nas relações de concorrência. Por seu turno, as políticas de fomento da pesca artesanal por meio de subsídios, linhas de crédito e estímulos a determinadas tecnologias, embora bem menos pujantes do que aquelas voltadas para o setor industrial (Diegues, 1983; 1995; Azevedo \& Pierri, 2014), foram importantes para estimular e dar condições para esse tipo de resposta. Além disso, por não contemplarem a preocupação com a sustentabilidade ecológica e com a legalidade das práticas, promoveram padrões de uso ilegais e potencialmente destrutivos (Andriguetto-Filho et al., 2014; Caldeira \& Pierri, 2014).

\subsection{A disponibilidade de informações}

O uso eficiente e equitativo dos recursos comuns depende das informações disponíveis e das oportunidades para que os usuários compreendam os efeitos das suas ações no sistema de recursos (Oakerson, 1992; Thomson et al., 1992). Idealmente, isso requer o monitoramento constante da condição dos recursos, das variações nos padrões de uso e dos impactos dessa variação na base de recursos (Ostrom, 1990; 1992).

Algumas instituições de pesquisa têm avançado na produção de informações sobre o funcionamento dos ecossistemas marinhos e estuarinos do litoral do Paraná ${ }^{6}$. Entretanto, existem importantes lacunas de informações necessárias para orientar os processos de tomada de decisão para o manejo dos recursos. A região não conta com estratégias contínuas e sistemáticas de monitoramento da pesca (práticas utilizadas, desembarques, níveis de esforço, rendimento das capturas, rendimento econômico, etc.) e faltam informações relevantes sobre a biologia e a ecologia de peixes, camarões e outros organismos marinhos, bem como sobre a atividade pesqueira local e seus impactos ecológicos. A situação é ainda mais complicada porque a condição dos recursos que sustentam a pesca local depende também dos usos praticados por pescadores de outras regiões. A influência de outros fatores antrópicos, tais como a poluição urbana e industrial,

\footnotetext{
6 Entre as instituições de destaque na produção de informações está o Centro de Estudos do Mar (www.cem.ufpr.br), unidade da UFPR criada em 1982 que conta com laboratórios de pesquisa em áreas da Oceanografia (biológica, física, química e geológica) e na área socioambiental. Na ictiologia e biologia pesqueira, merecem destaque o Laboratório de Ictiologia e o Laboratório de Biologia de Peixes. O Laboratório de Ictiologia Estuarina, vinculado ao Departamento de Zoologia da UFPR, também tem produzido informações com potencial para subsidiar a gestão pesqueira.
} 
também deve ser levada em conta. Embora relativamente bem preservada, a zona costeira paranaense tem sofrido impactos ecológicos significativos, tais como o despejo de efluentes domésticos, dragagens e vazamentos de óleo e outros produtos químicos (Lana et al., 2001; Noernberg et al., 2008). Devido à ampla distribuição espacial dos estoques acessados pelos pescadores locais, esses são afetados por perturbações em outras regiões do país e do mundo.

Nessas circunstâncias, o conhecimento científico produzido está longe de demonstrar precisamente os efeitos das diferentes modalidades e intensidades de uso praticadas pelos pescadores da região nos ecossistemas e na base de recursos. Da mesma forma, não existem informações para subsidiar análises precisas dos impactos das medidas de manejo na economia pesqueira local. Isso limita as condições para que os pescadores do litoral do Paraná avaliem as consequências de suas ações, dificultando o aprendizado social para a realização de estratégias coordenadas para o uso sustentável dos recursos, como o manejo adaptativo baseado na experimentação e no olhar atento aos feedbacks ambientais. Outro ponto crítico é que o conhecimento gerado não tem sido compartilhado com os usuários locais, assim como não existem oportunidades consistentes para a interação entre o conhecimento científico e o conhecimento ecológico local.

Durante as atividades do projeto, a falta de informações foi repetidamente utilizada por pescadores como justificativa para o questionamento da efetividade de algumas normas. Também foram recorrentes alegações de que estabelecer restrições à pesca do litoral paranaense não resolve o problema, sendo que os esforços dos gestores deveriam ser dirigidos ao controle de outras fontes de perturbação dos estoques pesqueiros e ecossistemas (pesca industrial de outros estados, pesca amadora, atividades portuárias, contaminação dos corpos d'água, etc.).

Nas dinâmicas para a elaboração de propostas de alteração na legislação, a falta de informações limitou a avaliação dos impactos socioeconômicos e ecológicos do quadro normativo vigente, bem como dos potenciais efeitos das sugestões de alteração da legislação apresentadas. Isso configura um impasse no que se refere ao conflito entre os interesses econômicos dos pescadores e os imperativos para a conservação dos recursos impostos pela legislação. De um lado, os pescadores alegam a inviabilidade econômica de algumas restrições e defendem que algumas de suas práticas atualmente proibidas não causam danos nos ecossistemas e recursos. Do outro lado, os técnicos responsáveis pela gestão dos recursos reconhecem que as incertezas e a limitação em termos de informação resultam em alto grau de subjetividade da gestão. Entretanto, advogam que, considerando o quadro de sobre-exploração dos recursos, a gestão pesqueira deve buscar reduzir os riscos, pendendo para o lado da conservação. Ainda de acordo com os técnicos, os pescadores devem se organizar e empreender parcerias com instituições de pesquisa para comprovar a sustentabilidade ecológica das práticas que defendem. Trata-se da inversão do ônus da prova, colocando sobre os interessados em realizar determinado uso a responsabilidade de comprovar que a atividade proposta não representa risco ao sistema de recursos. A postura dos técnicos está em sintonia com o princípio da precaução, reconhecido globalmente como fundamental para a salvaguarda dos recursos e, consequentemente, para a manutenção da própria atividade pesqueira (FAO, 1995; Berkes et al., 2001; Jentoft, 2007). 


\section{Considerações finais}

\subsection{Recomendações para a gestão participativa da pesca no litoral do Paraná}

No caso da pesca do litoral do Paraná, assim como verificado em pescarias de diversas regiões do Brasil e do mundo (Berkes et al., 2001; Pomeroy \& Rivera-Guieb, 2006; Vasconcellos et al., 2007; Seixas et al., 2011; Gutiérrez et al., 2011), as condições não são favoráveis em relação a alguns fatores críticos para a gestão participativa e o sucesso desse tipo de abordagem está condicionado à realização de uma série de ações.

No campo institucional, uma medida primordial é a criação de um arranjo que agregue os processos de tomada de decisão em nível estadual de gestão. Isso evitaria a atuação dispersa e independente dos órgãos ambientais e facilitaria a aproximação, o entendimento e a participação de usuários no processo. Também é preciso aprimorar as conexões com níveis mais elevados de governança, tais como o recorte Sul/Sudeste e o nível nacional. Os arranjos deveriam envolver representantes do setor produtivo, órgãos governamentais envolvidos no manejo pesqueiro e outros atores, como ONGs e instituições de pesquisa e extensão.

As atividades do projeto buscaram abranger a totalidade territorial (localidades pesqueiras) e funcional (escala de produção, tecnologias de pesca, área de atuação, recursos acessados, etc.) dos pescadores do litoral paranaense. Esse cuidado permitiu a representação dos principais interesses dos pescadores da região no que se refere às normas de pesca. Contudo, a continuidade dos debates e a busca pela resolução dos conflitos demandaria processos contínuos de levantamento de informação, geração de consensos e acordos entre os interesses envolvidos. Tal como recomendado pela literatura (Berkes et al., 2001; Pomeroy \& Rivera-Guieb, 2006), os aspectos operacionais de cada processo decisório (atores envolvidos, escalas consideradas, metodologias de participação e levantamento de informações) devem ser definidos caso a caso, de acordo com aquilo que está em jogo.

No litoral do Paraná, a gestão participativa requer ações de empoderamento dos pescadores para o engajamento na gestão. É necessário aumentar o nível de conhecimento dos pescadores sobre o funcionamento dos arranjos de governança, bem como desenvolver mecanismos para manter a classe pesqueira informada acerca das novidades no âmbito da gestão (assuntos em pauta, datas e locais de eventos, atualização da legislação, resultados alcançados, etc.). Estratégias contínuas de comunicação envolvendo palestras, materiais informativos e uso de meios de comunicação como jornais, rádios e televisão podem ser interessantes nesse sentido (Berkes et al., 2001; Pomeroy \& Rivera-Guieb, 2006). Também é preciso investir no fortalecimento de organizações e na capacitação de lideranças para a representação apropriada, tanto da diversidade de interesses quanto dos interesses comuns entre os pescadores da região.

A melhora do desempenho da gestão também demanda esforços intensivos de levantamento e disponibilização de informações para orientar as decisões. Para isso, não basta ampliar investimentos em pesquisas científicas relacionadas ao tema, é preciso aproximar a pesquisa do processo gestionário e investir na interação complementar entre o conhecimento científico e o conhecimento tradicional. Além de contribuir para a definição de temas ou pesquisas prioritárias e o direcionamento de esforços para o preenchimento de lacunas de informações importantes, isso aumentaria a legitimidade e a aceitação das normas de uso pelos pescadores da região. 
Outro problema que deve ser combatido é a falta de registros sistemáticos e contínuos de variáveis importantes, como de esforço de pesca, de capturas e de rendimento econômico. Em função da pulverização dos desembarques da região, métodos convencionais de obtenção das informações, por meio de amostragens feitas por agentes externos, se tornam demasiadamente custosos. Uma alternativa são sistemas participativos em que os pescadores realizam o registro das informações sobre suas pescarias. Contudo, as discussões sobre a obrigatoriedade do preenchimento do Mapa de Bordo ocorridas nos seminários e experiências no âmbito do monitoramento participativo dos desembarques pesqueiros desenvolvidas pelo IPÊ revelaram importantes obstáculos para o sucesso desse tipo de trabalho. Além de questões operacionais, como dificuldades para o preenchimento de informações pelos pescadores e custo relativamente alto para manter monitores locais para registrar os desembarques, observa-se que os pescadores são receosos em fornecer informações, tanto pela ilegalidade de muitas de suas práticas quanto pelo medo de terem os encargos tributários aumentados caso revelem os reais rendimentos. Assim, além de esclarecer a importância do instrumento, há que se investir no desmantelamento da estrutura de incentivos para a sonegação das informações (adequação das normas ambientais e das questões tributárias ou garantias que os pescadores não serão sancionados de acordo com as informações declaradas).

As atividades do projeto também evidenciaram que a criação de regras de forma democrática e devidamente embasadas, assim como a fiscalização eficiente das mesmas, são condições necessárias, mas não suficientes, para a busca de uma pesca socialmente justa, economicamente eficiente e ecologicamente prudente no litoral do Paraná. Se o processo de criação institucional não for acompanhado de cuidados com o funcionamento dos arranjos de produção, além da reprodução e da intensificação das desigualdades sociais no âmbito da pesca, corre-se o risco das instâncias de participação para a gestão dos recursos não serem utilizadas para a construção de padrões de interação cooperativos que favoreçam a viabilidade da pesca no presente e no futuro, mas sim como meras instâncias para que os usuários reclamem das restrições e tentem minimizar os efeitos negativos imediatos das medidas de manejo na economia de suas unidades produtivas. Entre as ações que podem ser desenvolvidas estão o estímulo a tecnologias compatíveis com os imperativos de conservação dos recursos e ecossistemas, a diminuição da competição entre os pescadores locais através do apoio à formação de unidades produtivas fundadas em relações sociais de produção solidárias (parcerias, sociedades, cooperativas, etc.) e a melhoria das condições de comercialização por meio de ações de capacitação, aprimoramento de infraestrutura e estratégias para contornar os efeitos da concorrência da pesca industrial e da aquicultura, como a criação de produtos que agreguem valor regional e possuam valor de uso diferenciado (Caldeira \& Pierri, 2014).

\subsection{O papel do Estado}

A atuação do Estado tem sido fundamental na configuração dos principais problemas e conflitos envolvendo o ordenamento pesqueiro no litoral do Paraná. Além de promoverem o crescimento desmedido da pesca industrial, causando o acirramento da competição e dos conflitos de uso entre pescadores de pequena e grande escala, as políticas de fomento do setor geraram mudanças na própria pesca local que, no intuito de sobreviver no mercado, empreende estratégias pujantes de intensificação do esforço 
e se transforma em mais um elemento de degradação da base de recursos. Contraditoriamente, o mesmo Estado, na figura dos órgãos encarregados da gestão dos recursos, busca desesperadamente conter a pressão ambiental exercida pelas forças produtivas que ajudou a fomentar. Para tanto, sobretudo a partir da década de 1990, lança mão de um quadro normativo complexo, construído em condições limitadas em termos de informação, sem a participação efetiva dos pescadores locais e que, apesar de altamente restritivo em relação às práticas de pesca da região, tem se mostrado inoperante no sentido de balizar as atitudes dos usuários e promover a conservação dos recursos e ecossistemas. A atuação ineficiente e contraditória do Estado coloca os pescadores da região em condição de vulnerabilidade, não apenas pela competição desigual com setores mais produtivos e pela degradação dos recursos pesqueiros, mas também pela ilegalidade de muitas de suas práticas.

A gestão participativa representa uma importante via para a busca de soluções para esses e outros problemas e conflitos da atividade pesqueira da região. Contudo, a efetividade desse tipo de abordagem demanda ações consistentes e contínuas em diversas frentes, tais como aquelas recomendadas no presente artigo. Isso só será possível mediante real interesse do Estado para a construção de modelos de desenvolvimento e de gestão pesqueira adequados às especificidades da região, em que os pescadores locais sejam protagonistas. Infelizmente, apesar da aparente preocupação governamental em promover a gestão compartilhada, expressa no discurso e em algumas iniciativas do governo, essa parece ser uma realidade distante, considerando a atual tendência em termos de políticas públicas para o setor. No plano de fomento, desde meados da década de 2000, observa-se nova conjuntura de forte atuação governamental para impulsionar o crescimento do setor pesqueiro nacional sem a devida consideração das consequências socioambientais, sendo a pesca industrial e a aquicultura os agentes escolhidos para viabilizar esse crescimento (Azevedo \& Pierri, 2013; 2014). No plano das medidas de ordenamento pesqueiro, os anos seguintes ao encerramento das atividades do projeto (2010) têm sido marcados pela continuidade da criação de normas sem a participação da classe pesqueira local e que, se fiscalizadas com rigor, podem comprometer os resultados econômicos de suas unidades produtivas, tais como a Instrução Normativa Interministerial do MPA/MMA n. 12, de 22 de agosto de 2012, que estabelece normas para a pesca de emalhe nas regiões Sul e Sudeste; a Portaria do MMA n. 445, de 17 de dezembro de 2014, que atualiza a lista nacional de espécies ameaçadas de extinção e estabelece restrições à sua pesca; e a Portaria Interministerial do MPA/MMA n. 4, de 14 de maio de 2015, que regula a pesca da tainha nas regiões Sul e Sudeste.

\section{Agradecimentos}

Ao MPA, pelo financiamento do Projeto "Nas Malhas da Inclusão". A todos os técnicos, pesquisadores e gestores envolvidos. Aos pescadores e pescadoras do litoral do Paraná pela receptividade, confiança e comprometimento durante as atividades. 


\section{Referências}

Abdallah, P. R.; Sumaila, U. R.An historical account of Brazilian public policy on fisheries subsidies. Marine Policy, 31, 444-450, 2007. doi: 10.1016/j.marpol.2007.01.002

Andriguetto-Filho, J. M.; Chaves, P. T.; Santos, C.; Liberati, S. A. Diagnóstico da pesca no litoral do Estado do Paraná. In: Isaac, V. J.; Martins, A. S.; Haimovici, M.; Andriguetto-Filho, J. M. (Orgs.). A pesca marinha e estuarina do Brasil no início do século XXI: recursos, tecnologias, aspectos socioeconômicos e institucionais. Belém, Brasil: Universidade Federal do Pará, 2006. p. 117-140.

Andriguetto-Filho, J. M.; Pierri, N. Participación de pescadores artesanales en el diseño de un proyecto de implantación de arrecifes artificiales en el Sur de Brasil. Cultura-Hombre-Sociedad, 22, 95-113, 2012.

Andriguetto-Filho, J. M.; Krull, R.; Feitosa, S. Contradições históricas entre gestão e fomento e a evolução da pesca de arrasto de camarão na plataforma interna do Paraná. In: Haimovici, M.; Andriguetto-Filho, J. M.; Sunye, P. S. A pesca marinha e estuarina no Brasil: estudos de caso multidisciplinares. Rio Grande: Editora da FURG, 2014. p. 87-99.

Azevedo, N. T.; Pierri, N. Brazil. Fishery Policy. Short-term model. The government of Brazil is backing increased production through promoting industrial fisheries and aquaculture to the detriment of small-scale fisheries. Samudra Report, 64, 34-41, 2013. Disponível em: <http://www.icsf. net/en/samudra/article/EN/64>.

Azevedo, N. T.; Pierri, N. A política pesqueira no Brasil (2003-2011): a escolha pelo crescimento produtivo e o lugar da pesca artesanal. Desenvolvimento e Meio Ambiente, 32, 61-80, 2014. doi: 10.5380/dma.v32i0.35547

Baland, J. M.; Platteau, J. P. The Ambiguous Impact of Inequality on Local Resource Management. World Development, 27(5), 773-788, 1999.

Berkes, F. Conexões institucionais transescalares. In: Vieira, P. F.; Berkes, F.; Seixas, C. S. (Orgs.). Gestão integrada e participativa de recursos naturais. Florianópolis: APED, 2005. p. 293-332.

Berkes, F.; Mahon, R.; McConney, P.; Pollnac, R.; Pomeroy, R. Managing small-scale fisheries: alternative directions and methods. Ottawa, Canada: International Development Research Centre, 2001.

Brandini, F. P. Marine biodiversity and sustainability of fishing resources in Brazil: a case study of the coast of Paraná state. Regional Environmental Change, 13, 1-11, 2013. doi: 10.1007/s10113-013-0458-y

Brasil. Decreto n. 6.981, de 13 de outubro de 2009. Brasília: DOU 14/10/2009.

Caldeira, G. A.; Pierri, N. As relações econômicas e a gestão compartilhada de recursos comuns: o caso da pesca marinha em Pontal do Paraná, Sul do Brasil. Desenvolvimento e Meio Ambiente, 32, 119-137, 2014. doi: 10.5380/ dma.v32i0.35927

Diegues, A C. S. Pescadores, camponeses e trabalhadores do mar. São Paulo: Ática, 1983.

Diegues, A C. S. Povos e mares: leituras em socioantropologia marítima. São Paulo: NUPAUB-USP, 1995.

FAO - Food and Agriculture Organization of the United Nations. Code of Conduct for Responsible Fisheries. Rome: FAO. 1995. Disponível em: <http://www.fao.org/3/av9878e.pdf>.

FAO - Food and Agriculture Organization of the United Nations - Fishery Resources Division. Indicators for sustainable development of marine capture fisheries. FAO Technical Guidelines for Responsible Fisheries. N. 8. Rome: FAO. 1999. 68 p. Disponível em: <http://www.fao. org/DOCREP/004/X3307E/X3307E00.HTM>. Acesso em 03 jul. 2007.

Franco, A. C. N. P.; Schwarz Junior, R.; Pierri, N.; Santos, G. C. Levantamento, sistematização e análise da legislação aplicada ao defeso da pesca de camarões para as regiões Sudeste e Sul do Brasil. Boletim do Instituto de Pesca, 35, 687-699, 2009. Disponível em: <ftp://ftp.sp.gov.br/ftppesca/35_4_687-699.pdf $>$.

Gutiérrez, N. L.; Hilborn, R.; Defeo, O. Leadership, social capital and incentives promote successful fisheries. Nature, 470, 386-389, 2011. doi: 10.1038/nature09689

IAP - Instituto Ambiental do Paraná. Portaria n. 85, de 19 de junho de 2009. Curitiba: DOE de 25/06/2009. 
IBAMA - Instituto Brasileiro de Meio Ambiente e Recursos Naturais Renováveis. Portaria do IBAMA n. 133-N, de 8 de dezembro de 1994. Brasília: DOU de 09/12/1994.

IBAMA - Instituto Brasileiro de Meio Ambiente e Recursos Naturais Renováveis. Portaria IBAMA n. 121-N, de 24 de agosto de 1998. Brasília: DOU de 25/08/1998.

IBAMA - Instituto Brasileiro de Meio Ambiente e Recursos Naturais Renováveis. Portaria n. 12, de 20 de março de 2003. Brasília: DOU de 21/03/2003.

IBAMA - Instituto Brasileiro de Meio Ambiente e Recursos Naturais Renováveis. Instrução Normativa n. 91, de 6 de fevereiro de 2006. Brasília: DOU de 07/02/2006.

IBAMA - Instituto Brasileiro de Meio Ambiente e Recursos Naturais Renováveis. Instrução Normativa n. 166, de junho de 2007. Brasília: DOU de 19/07/2007.

IBAMA - Instituto Brasileiro de Meio Ambiente e Recursos Naturais Renováveis. Portaria n. 171, de maio de 2008. Brasília: DOU de 12/05/2008.

IPARDES - Instituto Paranaense de Desenvolvimento Econômico e Social. Zoneamento do Litoral Paranaense. Curitiba: Fundação Édson Vieira, 1989.

Isaac, V. J.; Martins, A. S.; Haimovici, M.; Andriguetto-Filho, J. M. (Orgs.). A pesca marinha e estuarina do Brasil no início do século XXI: recursos, tecnologias, aspectos socioeconômicos e institucionais. v. 1, 1. ed. Belém: Editora Universitária da UFPA, 2006.

Jentoft, S. Limits of governability: Institutional implications for fisheries and coastal governance. Marine Policy, 31, 360-370, 2007. DOI: 10.1016/j.marpol.2006.11.003

Jentoft, S.; McCay, B. User participation in fisheries management: lessons drawn from international experiences. Marine Policy, 19(3), 227-246, 1995. DOI: 0308597X(94)00010-7

Kraemer, M. C. Malhas da pobreza: exploração do trabalho de pescadores artesanais da Baía de Paranaguá. Curitiba: Estante Paranista, 1982.

Lana, P. C.; Marone, E.; Lopes, R. M.; Machado, E. C. The subtropical estuarine complex of Paranaguá Bay. In: Seeliger, U.; Kjerfve, B. (Org.). Coastal Marine Ecosystems of Latin America. Berlin: Springer Verlag, 2001. p. 132-145.

Malheiros, H. Z.; Caldeira, G. A.; Mafra, T. V.; Gruntowski, A.; Tavares, D.; Vieira, M. E.; Medeiros, C. L.; Domit, L.;
Saupe, A. C.; Rodrigues, L. F.; Castella, P. R.; Saborido, N. C.; Ramos, M.; Fonseca, A. Cartilha da Gestão Participativa da Pesca no Litoral do Paraná. Instituto de Pesquisas Ecológicas, 2009. Disponível em: < http://www.ipe.org.br/ artigos-cientificos/293-cartilha-da-gestao-participativa-da-pesca-no-litoral-do-parana>. Acesso em: 20 fev. 2015.

Miranda, R. B. As relações sociedade/natureza sob a perspectiva de coevolução. Desenvolvimento e Meio Ambiente, 8, 77-96, 2003. doi: 10.5380/dma.v8i0.22055

MMA - Ministério do Meio Ambiente. Instrução Normativa n. 29, de 6 de dezembro de 2004. Brasília: DOU de $07 / 12 / 2004$.

MMA - Ministério do Meio Ambiente. Instrução Normativa $n$. 53, de 22 de novembro de 2005. Brasília: DOU de $24 / 11 / 2005$.

MMA - Ministério do Meio Ambiente. Portaria n. 445, de 17 de dezembro de 2014. Brasília: DOU 18/12/2014.

MPA - Ministério da Pesca e Aquicultura; MMA - Ministério do Meio Ambiente. Instrução Normativa Interministerial $n$. 12, de 22 de agosto de 2012. Brasília: DOU 24/08/2012.

MPA - Ministério da Pesca e Aquicultura; MMA - Ministério do Meio Ambiente. Portaria Interministerial n. 4, de 14 de maio de 2015. Brasília: DOU 15/05/2015.

Noernberg, M. A.; Angelotti, R.; Caldeira, G. A.; Sousa, A. F. R. Determinação da sensibilidade do litoral paranaense à contaminação por óleo. Brazilian Journal of Aquatic Science and Technology, 12, 49-59, 2008. doi: 10.14210/ bjast.v12n2.p49-59

Oakerson, R. Analyzing the commons: a framework. In: Bromley, D.W. (Ed.). Making the commons work: theory, practice, and policy. San Francisco, California: ICS Press, 1992. p. 41-59.

Ostrom, E. Governing the Commons: the evolution of institutions for collective action. Cambridge: Cambridge University Press, 1990.

Ostrom, E. The Rudiments of a Theory of the Origins, Survival, and Performance of Common Property Institutions. In: Bromley, D.W. (Ed.). Making the commons work: theory, practice, and policy. San Francisco, Califórnia: ICS Press, 1992. p. 293-316. 
Polinari, M. "Pescadores Artesanais", "caiçaras" e outros conceitos utilizados inadequadamente. In: Lima, R. E. Meio ambiente e desenvolvimento no litoral do Paraná: Diagnóstico. Brasília: Editora UFPR-NIMAD/CNPq, 1998. p. 117-136.

Pomeroy, R.S.; Williams, M, J. Fisheries co-management and small-scale fisheries: a policy brief. Manila: International Center for Living Aquatic Resources Management, 1994. $15 \mathrm{p}$.

Pomeroy, R.S.; Rivera-Guieb, R. Fishery co-management: a practical handbook. IDRC/CADI, 2006.

Quivy, R.; Campenhoudt, L. V. Manual de investigações em ciências sociais. Lisboa: Ed. Gradiva, 1992.

SEMA - Secretaria Estadual de Meio Ambiente. Resolução n. 016 de 30 de março 2009. Disponível em: <http://www. portosdoparana.pr.gov.br/arquivos/File/RESOLUCAO_ SEMA_16_2009.pdf $>$. Acesso em:09 jul. 2015.

Seixas, C. S. Abordagens e técnicas de pesquisa participativa em gestão de recursos naturais. In: Vieira, P. F.; Berkes,
F.; Seixas, C. S. (Orgs.). Gestão integrada e participativa de recursos naturais. Florianópolis: APED, 2005. p. 73-105.

Seixas, C. S.; Kalikoski, D. C.; Almudi, T.; Batista, V. S.; Costa, A. L.; Diogo, H. L.; Ferreira, B. P.; Futemma, C. R. T.; Moura, R. L.; Ruffino, M. L.; Salles, R.; Thé, A. P. G. Gestão compartilhada do uso de recursos pesqueiros no Brasil: elementos para um programa nacional. Ambiente \& Sociedade, 14(1), 23-44, 2011. doi: 10.1590/S1414-753X2011000100003.

Thomson, J. T.; Feeny, D.; Oakerson, R. J. Institutional dynamics: the evolution and dissolution of common property resource management. In: Bromley, D. W. (Ed.). Making the commons work: theory, practice, and policy. San Francisco, California: ICS Press, 1992. p. 129-160.

Vasconcellos, M.; Diegues, A. C.; Sales, R. R. Limites e possibilidades na gestão da pesca artesanal costeira. In: Costa, A. L. (Org.). Nas redes da pesca artesanal. Brasília: IBAMA, 2007. p. 2-70. 